Provided for non-commercial research and education use. Not for reproduction, distribution or commercial use.

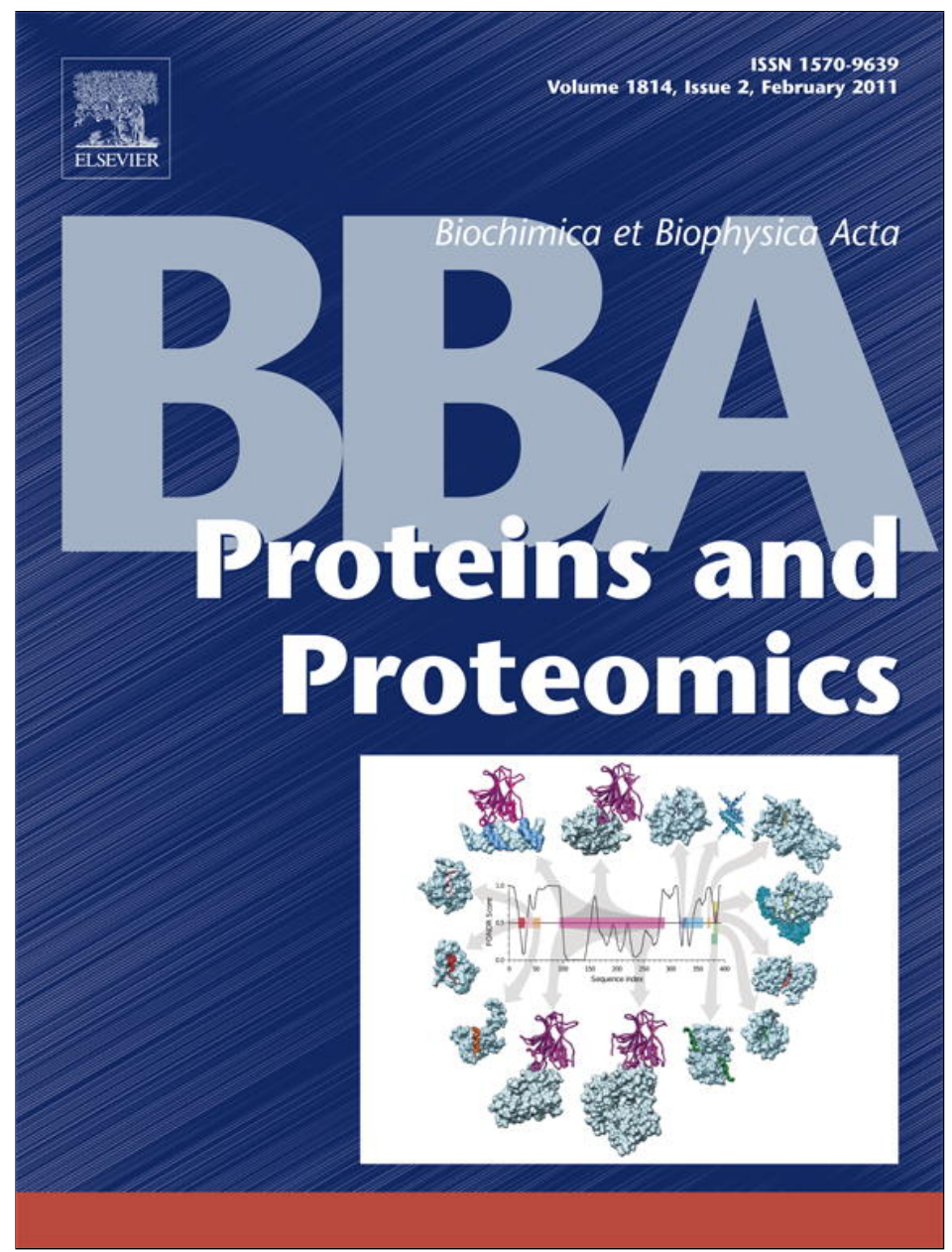

(This is a sample cover image for this issue. The actual cover is not yet available at this time.)

This article appeared in a journal published by Elsevier. The attached copy is furnished to the author for internal non-commercial research and education use, including for instruction at the authors institution and sharing with colleagues.

Other uses, including reproduction and distribution, or selling or licensing copies, or posting to personal, institutional or third party websites are prohibited.

In most cases authors are permitted to post their version of the article (e.g. in Word or Tex form) to their personal website or institutional repository. Authors requiring further information regarding Elsevier's archiving and manuscript policies are encouraged to visit:

http://www.elsevier.com/copyright 


\title{
The role of a disulfide bridge in the stability and folding kinetics of Arabidopsis thaliana cytochrome $c_{6 \mathrm{~A}}$
}

\author{
Jody M. Mason ${ }^{a}$, Derek S. Bendall ${ }^{\mathrm{b}}$, Christopher J. Howe ${ }^{\mathrm{b}}$, Jonathan A.R. Worrall ${ }^{\mathrm{a}, *}$ \\ a Department of Biological Sciences, University of Essex, Wivenhoe Park, Colchester, CO4 3SQ UK \\ b Department of Biochemistry, University of Cambridge, Downing Site, Tennis Court Road, Cambridge CB2 1QW, UK
}

\section{A R T I C L E I N F O}

\section{Article history:}

Received 25 July 2011

Received in revised form 11 October 2011

Accepted 26 October 2011

Available online 31 October 2011

\section{Keywords:}

Cytochrome $c_{6}$

Disulfide bond

Protein folding

Heme redox potentia

\begin{abstract}
A B S T R A C T
Cytochrome $c_{6 \mathrm{~A}}$ is a eukaryotic member of the Class I cytochrome $c$ family possessing a high structural homology with photosynthetic cytochrome $c_{6}$ from cyanobacteria, but structurally and functionally distinct through the presence of a disulfide bond and a heme mid-point redox potential of $+71 \mathrm{mV}$ ( $v s$ normal hydrogen electrode). The disulfide bond is part of a loop insertion peptide that forms a cap-like structure on top of the core $\alpha$-helical fold. We have investigated the contribution of the disulfide bond to thermodynamic stability and (un)folding kinetics in cytochrome $c_{6 \mathrm{~A}}$ from Arabidopsis thaliana by making comparison with a photosynthetic cytochrome $c_{6}$ from Phormidium laminosum and through a mutant in which the Cys residues have been replaced with Ser residues (C67/73S). We find that the disulfide bond makes a significant contribution to overall stability in both the ferric and ferrous heme states. Both cytochromes $c_{6 \mathrm{~A}}$ and $c_{6}$ fold rapidly at neutral $\mathrm{pH}$ through an on-pathway intermediate. The unfolding rate for the C67/73S variant is significantly increased indicating that the formation of this region occurs late in the folding pathway. We conclude that the disulfide bridge in cytochrome $c_{6 \mathrm{~A}}$ acts as a conformational restraint in both the folding intermediate and native state of the protein and that it likely serves a structural rather than a previously proposed catalytic role.
\end{abstract}

(c) 2011 Elsevier B.V. All rights reserved.

\section{Introduction}

Cytochrome $c_{6}$ (cyt $c_{6}$ ) is a member of the Class I cyt $c$ family, which is synthesized under copper deficient conditions in cyanobacteria and functions to transfer reducing equivalents from cyt $f$ of the membrane bound cyt $b_{6} f$ complex to photosystem I [1]. This function is possible due to cyt $c_{6}$ having a heme mid-point redox potential $\left(\mathrm{E}_{\mathrm{m}}\right)$ in the region of $+350 \mathrm{mV} v s$ normal hydrogen electrode (NHE) which is thermodynamically favourable for electrons to be shuttled between the two membrane bound components. Recently, genomic and bioinformatic approaches have uncovered cyt $c_{6}$-like proteins present in plants, green algae [2-4], and certain cyanobacteria [5], which are distinct from the photosynthetic cyt $c_{6}$ members. The plant cyt $c_{6}$-like protein was the first of these to be discovered and was subsequently named cyt $c_{6 \mathrm{~A}}[4]$. In keeping with this nomenclature, the cyt $c_{6}$-like proteins identified in certain cyanobacteria have been named cyt $c_{6 \mathrm{~B}}$ and $c_{6 \mathrm{C}}$ [5], but their functions have yet to be determined. However, for cyt $c_{6 \mathrm{~A}}$ and cyt $c_{6 \mathrm{~B}}$ current evidence confirms that they are likely to be functionally distinct

Abbreviations: Cyt, cytochrome; At, Arabidopsis thaliana; Pl, Phormidium laminosum; $\mathrm{E}_{\mathrm{m}}$, heme mid-point redox potential; LIP, loop insertion peptide; wt, wild-type; Amp, ampicillin; Cam, chloramphenicol; LB, lysogeny-broth; IPTG, isopropyl $\beta$-D-1-thiogalactopyranoside; $\mathrm{GuHCl}$, guanidine hydrochloride; $\mathrm{CD}$, Circular dichroism; NHE, normal hydrogen electrode; DTT, Dithiothreitol; DTNB, 5,5'-dithiobis(2-nitrobenzoic acid).

* Corresponding author. Tel.: + 441206872095.

E-mail address: jworrall@essex.ac.uk (J.A.R. Worrall). from photosynthetic cyt $c_{6}$ due to their $\mathrm{E}_{\mathrm{m}} \mathrm{s}$ being $>200 \mathrm{mV}$ lower. This property makes them incapable of functioning in the photosynthetic pathway in the same way as cyt $c_{6}[6-8]$.

Structural studies on Arabidopsis thaliana (At) $\mathrm{cyt}_{\mathrm{C}} \mathrm{c}_{6 \mathrm{~A}}$ have revealed a high structural homology to photosynthetic cyts $c_{6}[9,10]$. Differences primarily arise through the presence of a loop insertion peptide (LIP) consisting of 12 amino acids located between helices 3 and 4 [10] (Fig. 1A). The LIP houses two Cys residues (C67 and C73), that are 5 residues apart and form a disulfide bond $[9,10]$ (Fig. 1A). This feature is not found in cyt $c_{6}, c_{6 \mathrm{~B}}$ or $c_{6 \mathrm{C}}$ and is thus unique to cyt $c_{6 \mathrm{~A}}$ members [5]. No conformational change in the disulfide bond or the LIP upon heme oxidation state change has been detected [10] and a number of hypotheses suggesting a catalytic role for this disulfide containing LIP to support possible cellular function have been put forward $[11,12]$.

Folding and/or stability studies on the cyt $c_{6}$ family (which includes cyts $c_{6 \mathrm{~A}}, c_{6 \mathrm{~B}}$ and $c_{6 \mathrm{C}}$ ) have received relatively little attention [13-16] compared to other Class I cyt $c$ members. The folding and stability of Class I mitochondrial horse and yeast cyts $c$ have been extensively studied and it is well documented that the heme and axial ligands influence the folding landscape [17-22]. The covalently bound heme can be considered to guide the polypeptide chain towards its folding pathway(s) $[23,24]$ and has led to the notion that this non-polar co-factor carries part of the information about the native fold. Similarly, a disulfide bond also has the potential to influence the folding pathway. For example it has been shown that the location of a disulfide bond in a protein can act to bring residues of the folding nucleus into proximity and facilitate the 
A
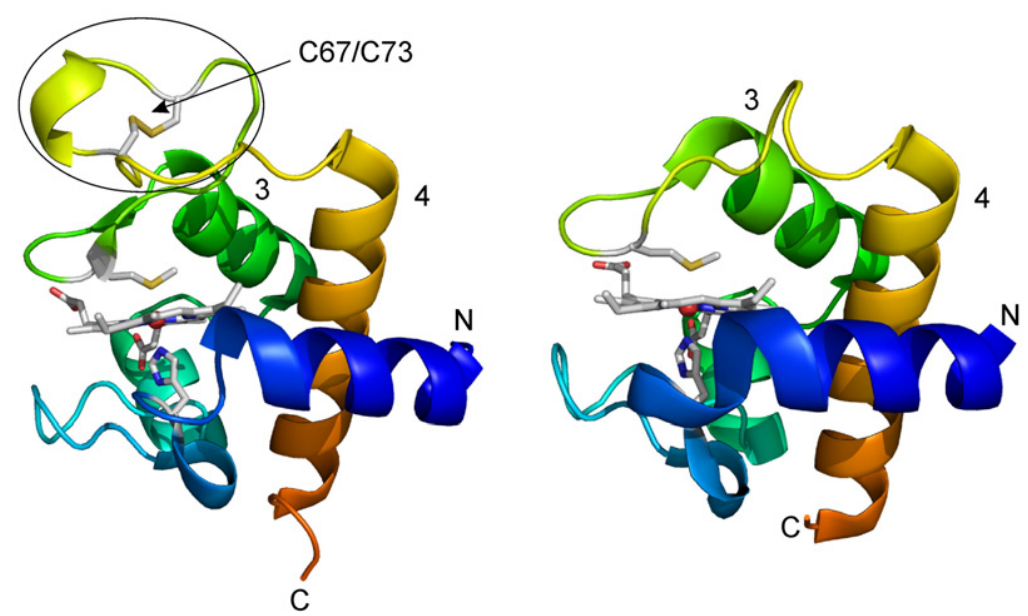

B

Arabidopsis_crt_c6A/1-105 Phormidium_cytc6/1-86

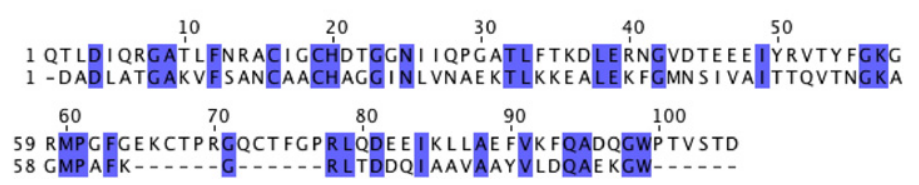

Fig. 1. (A) Cartoon representation with rainbow colouring from the $\mathrm{N}$ - to $\mathrm{C}$-terminus of the $\mathrm{X}$-ray crystal structures of $A t$ cyt $c_{6 \mathrm{~A}}$ (PDB code $2 \mathrm{CE} 0$ ), left, and $P l$ cyt $c_{6}$ (PDB code $2 \mathrm{~V} 08$ ), right. The heme iron is represented as a red sphere and the heme, its axial ligands and the disulfide bridge (C67/C73) are all drawn in sticks. Helices 3 and 4 are labelled and are referred to in the text. The LIP region in At cyt $c_{6 \mathrm{~A}}$ is indicated with a circle. (B) Amino acid sequence alignment of At cyt $c_{6 \mathrm{~A}}$ and Pl cyt $c_{6}$ with conserved amino acids highlighted in blue. For interpretation of the references to colour in this figure legend, the reader is referred to the web version of this article.

folding to the native state [25-30]. A common misconception is that disulfide bonds always provide stability in proteins. The energetic gain from naturally occurring disulfide bonds can vary hugely [31] and catalytic or allosteric disulfide bonds do not generally have a stabilizing effect [32].

As well as studies with mitochondrial cyt $c$, the folding kinetics of several bacterial cyts $c$ have also been reported [33-38]. These studies have highlighted that despite considerable variation in sequence and thermodynamic stabilities inherent amongst Class I members, a consensus folding mechanism exists that involves the transient population of a compact intermediate with conserved structural features [34-36].

In this study we report on the thermodynamic stabilities and folding properties of the photosynthetic cyt $c_{6}$ from the cyanobacterium Phormidium laminosum $(\mathrm{Pl})$ and $A t$ cyt $c_{6 \mathrm{~A}}$. Amino acid sequence alignment and X-ray crystal structures of these two members of the cyt $c_{6}$ family are depicted in Fig. 1. No kinetic folding profile for a disulfide bond containing cyt $c$ has been previously reported, and therefore the presence of a disulfide bond in cyt $c_{6 \mathrm{~A}}$ affords an interesting opportunity to assess its contribution to the folding kinetics in the cyt $c_{6}$ family and more generally to the consensus folding mechanism of Class I cyts $c$ [35]. To aid with determining the kinetic mechanism and to ascertain the contribution to overall protein stability, the two Cys residues forming the disulfide bond have been replaced with Ser residues to create the $667 / 73 \mathrm{~S}$ double variant. The results of this study are strongly in favour of the disulfide bond stabilizing the conformation of the LIP and support a recent proposal that the LIP may serve as a recognition site/motif for a protein partner [7], rather than in a catalytic role $[11,12]$.

\section{Materials and methods}

\subsection{Protein expression and purification}

All proteins were expressed in Escherichia coli using a dual plasmid strategy. The vector pGEMPIc6 $\left(A^{2} p^{r}\right)$ harbouring the wild-type (wt) gene of Phormidium laminosum $(\mathrm{Pl})$ cyt $c_{6}[6]$ was introduced by transformation into E. coli BL21(DE3) cells containing the pEC86 $\left(\mathrm{Cam}^{\mathrm{r}}\right)$ plasmid. This plasmid contains genes to express the necessary proteins to assist with covalent heme attachment [39]. The vector pBluAtc6a $\left(A m p^{r}\right)$ containing the wt $A$. thaliana $(A t)$ cyt $c_{6 A}$ gene was introduced by transformation into E. coli GM119 also containing the pEC86 plasmid. The C67/73S variant of At cyt $c_{6 \mathrm{~A}}$ was also transformed into $E$. coli GM119 containing the pEC86 plasmid [40]. Over-expression of the desired cyt began with starter cultures consisting of $10 \mathrm{~mL}$ lysogenybroth (LB) medium containing $100 \mu \mathrm{g} / \mathrm{mL}$ Amp and $25 \mu \mathrm{g} / \mathrm{mL}$ Cam for $6-8 \mathrm{~h}$ at which time the cultures were transferred to $2 \mathrm{~L}$ flasks containing $1.7 \mathrm{~L}$ of LB supplemented with a final concentration of $1 \mathrm{mM} \mathrm{FeCl}_{3}$ and growth continued at $30{ }^{\circ} \mathrm{C}$ with shaking $(170 \mathrm{rpm})$ overnight. For $\mathrm{Pl} \mathrm{cyt} c_{6}$ expression was induced by the addition of $100 \mathrm{mg} / \mathrm{L}$ of isopropyl $\beta$-D-1-thiogalactopyranoside (IPTG) after overnight growth. Cells were harvested after $72 \mathrm{~h}$ and purification of all over-expressed cyts was as previously described [10].

\subsection{General sample preparation}

Proteins were exchanged into $10 \mathrm{mM}$ potassium phosphate, $50 \mathrm{mM}$ potassium fluoride $\mathrm{pH} 7.0$ by ultrafiltration. Protein concentrations were determined by UV-vis spectroscopy using a molar extinction coefficient $\varepsilon=23 \mathrm{mM}^{-1} \mathrm{~cm}^{-1}$ at $553 \mathrm{~nm}$ for ferrous $P l$ cyt $c_{6}$ and $\varepsilon=26 \mathrm{mM}^{-1} \mathrm{~cm}^{-1}$ at $555 \mathrm{~nm}$ for ferrous cyt $c_{6 \mathrm{~A}}$ [40]. The ferric or ferrous protein was prepared by the addition of excess $\mathrm{K}_{3}[\mathrm{Fe}$ $(\mathrm{CN})_{6}$ ] or ascorbic acid, respectively, followed by removal using a PD10 column (GE Healthcare). Protein concentrations ranged between 15 and $65 \mu \mathrm{M}$ for thermal and chemical denaturation experiments and $110 \mu \mathrm{M}$ for kinetic experiments. Ultrapure guanidine hydrochloride $(\mathrm{GuHCl})$ was purchased from Fluka (>99\%) and a stock solution of $6 \mathrm{M}$ was prepared by dissolving solid $\mathrm{GuHCl}$ in $10 \mathrm{mM}$ potassium phosphate, $50 \mathrm{mM}$ potassium fluoride $\mathrm{pH} 7.0$, and filtered through a 0.22 -micron filter (Millipore) before use. The concentrations of $\mathrm{GuHCl}$ were determined through measurements of the solution refractive index using a refractometer. 


\subsection{Circular dichroism spectroscopy}

Circular dichroism (CD) measurements were carried out using an Applied Photophysics Chirascan CD spectrophotometer (Leatherhead, U.K.) with a thermostatted cell holder controlled by a Peltier system. Prior to kinetic folding experiments far-UV CD spectra at $20^{\circ} \mathrm{C}$ for all cyts to be studied were acquired in the range $280-190 \mathrm{~nm}$ to corroborate that they were folded.

\subsection{Equilibrium unfolding}

Equilibrium unfolding was monitored by far-UV CD spectroscopy. Changes in ellipticity $(\theta)$ at $222 \mathrm{~nm}$ were monitored for both chemical and thermal denaturation studies. A $6 \mathrm{M}$ stock solution of $\mathrm{GuHCl}$ was titrated into a sample to give the final desired [ $\mathrm{GuHCl}]$ with mixing facilitated by a magnetic stirrer. Thermal denaturation was monitored between 0 and $96^{\circ} \mathrm{C}$ with changes at $222 \mathrm{~nm}$ monitored at $1{ }^{\circ} \mathrm{C}$ intervals in stepping mode. To ascertain whether thermal denaturation was a reversible process, thermally denatured samples were cooled at $1{ }^{\circ} \mathrm{C}$ intervals and $\theta$ monitored at $222 \mathrm{~nm}$. Measurements at each temperature were allowed to equilibrate for $60 \mathrm{~s}$ before data acquisition. Sampling times for each data point at the desired [GuHCl] or temperature were $12 \mathrm{~s}$.

\subsection{Stopped-flow kinetic measurements}

Unfolding and folding reactions were monitored at $222 \mathrm{~nm}$ using an Applied Photophysics Chirascan CD spectrophotometer (Leatherhead, U.K.) fitted with a stopped-flow sample handling unit and thermostatted at $20{ }^{\circ} \mathrm{C}$ with a Thermo scientific neslab RTE-7 digital plus water circulator. Cyt samples for folding experiments were first unfolded in $\mathrm{GuHCl}$ to give final [ $\mathrm{GuHCl}$ ] between 4.46 and $4.8 \mathrm{M}$. Folding was initiated by mixing the unfolded protein against 10 volumes of a given [ $\mathrm{GuHCl}]$ to give a post-mix cyt concentration of $10 \mu \mathrm{M}$ and a post-mix [GuHCl] between 0.4 and $2.9 \mathrm{M}$. Unfolding was initiated by mixing a $110 \mu \mathrm{M}$ protein solution against 10 volumes of a given [GuHCl] to yield a post-mix cyt concentration of $10 \mu \mathrm{M}$ and a postmix [ $\mathrm{GuHCl}$ ] between 2.4 and $5.4 \mathrm{M}$. Changes in $\theta$ at $222 \mathrm{~nm}$ were followed over time ranges as short as $100 \mathrm{~ms}$ and as long as $40 \mathrm{~s}$. Each kinetic transient consisted of 1000 data points and was an average of at least three triggers.

\subsection{Data analysis}

Equilibrium unfolding data for chemical denaturation were fitted using an equation for two-state unfolding with the assumption of linear baselines for native and denatured cyts according to the method of Santoro and Bolen [41]

$\theta_{222 n m}=\frac{\left(\alpha_{N}+\beta_{N}[G u H C l]\right)+\left(\alpha_{D}+\beta_{D}[G u H C l]\right) \exp \left(\frac{-\Delta G_{D-N}{ }^{H_{2} O}+m[G u H C l}{R T}\right)}{1+\exp \left(\frac{-\Delta G_{D-N}{ }^{H_{2} O}+m[G u H C l}{R T}\right)}$

$\alpha_{N}$ and $\alpha_{D}$ correspond to the baseline values of the native and denatured protein at $0 \mathrm{M} \mathrm{GuHCl}$ respectively, and $\beta_{\mathrm{N}}$ and $\beta_{\mathrm{D}}$ to their respective dependence on [GuHCl] i.e. the slope. $\Delta \mathrm{G}_{\mathrm{D}-\mathrm{N}} \mathrm{H}_{2} \mathrm{O}$ is the free energy of denaturation in water and $m$ represents the dependence of the free energy of denaturation on $[\mathrm{GuHCl}]$. The fraction denatured $\left(\mathrm{F}_{\mathrm{D}}\right)$ at any given $[\mathrm{GuHCl}]$ was calculated from Eq. (2).

$F_{D}=\frac{\theta_{222 n m}-\left(\alpha_{N}+\beta_{N}[G u H C l]\right)}{\left(\alpha_{D}+\beta_{D}[G u H C l]\right)-\left(\alpha_{N}+\beta_{N}[G u H C l]\right)}$

The unfolding and folding transients for all proteins studied followed a first-order process and were fitted to a single-exponential function to yield first-order rate constants. The natural logarithms of the folding $\left(\mathrm{k}_{\mathrm{f}}\right)$ and unfolding $\left(\mathrm{k}_{\mathrm{u}}\right)$ rate constants were plotted against $[\mathrm{GuHCl}]$ and the data were fitted using Eq. (3)

$k_{o b s}=k_{F-I}+k_{I-F} /\left(1+1 / K_{I / U}\right)$

which describes a 3-state folding mechanism, assuming the presence of a folding intermediate. $\mathrm{k}_{\mathrm{I}-\mathrm{F}}$ and $\mathrm{k}_{\mathrm{F}-\mathrm{I}}$ are rate constants describing the forward and reverse reactions, respectively, between the folded and intermediate states (I) and $\mathrm{K}_{\mathrm{I} / \mathrm{U}}$ is the equilibrium constant $[\mathrm{I}] /[\mathrm{U}]$ for the rapid interconversion of the intermediate and denatured states.

\section{Results}

\subsection{Equilibrium unfolding of wt At cyt $c_{6 A}$ and Pl cyt $c_{6}$}

For all proteins used in this study the far-UV CD spectrum in the absence of denaturant exhibited two negative minima at 208 and $222 \mathrm{~nm}$, consistent with a fully folded protein dominated by $\alpha$-helical structure (Fig. 2A). In the presence of increasing [ $\mathrm{GuHCl}]$ or temperature, changes in $\theta$ at $222 \mathrm{~nm}$ were observed. The $\mathrm{GuHCl}$ data were converted to fraction unfolded using Eq. (2) and plotted as a function of [ $\mathrm{GuHCl}]$ (Figs. 2B and C). $\mathrm{GuHCl}$ induced unfolding was found to be a reversible process for all proteins studied as indicated by UV-vis and far-UV CD spectroscopies upon removal of $\mathrm{GuHCl}$ from the titration end-point sample (Figures S1 and S2 supporting information). The $\Delta \mathrm{G}_{\mathrm{D}-\mathrm{N}}{ }^{\mathrm{H}_{2} \mathrm{O}}$, and $m$ values reported in Table 1 were determined by fitting the chemical denaturation data to Eq. (1). Thermal denaturation was found not to be a reversible process (Figure S3 supporting information) and therefore the data were not used to extract thermodynamic parameters. Fig. 2D illustrates the thermal denaturation profiles, which, although irreversible, indicate that the approximate midpoint melting transition for $\mathrm{Pl}$ cyt $c_{6}$ is shifted to the right with respect to At cyt $c_{6 \mathrm{~A}}$ suggesting a slight increase in resistance to temperature unfolding (Table 1). Reducing the heme to the ferrous state in $P l$ cyt $c_{6}$ yields a significant increase in the $\Delta \mathrm{G}_{\mathrm{D}-\mathrm{N}} \mathrm{H}_{2} \mathrm{O}$ and $\mathrm{C}_{\mathrm{m}}$ (the denaturant concentration required to induce $50 \%$ unfolding) by $2.3 \mathrm{kcal} / \mathrm{mol}$ and $0.5 \mathrm{M}$, respectively (Table 1 ). These differences are not as pronounced for ferrous At cyt $c_{6 \mathrm{~A}}$, where only a $1.1 \mathrm{kcal} / \mathrm{mol}$ increase in $\Delta \mathrm{G}_{\mathrm{D}-\mathrm{N}}{ }^{\mathrm{H}_{2} \mathrm{O}}$ is observed with respect to the ferric form, and no significant change in $C_{m}$ is observed (Table 1).

\subsection{Equilibrium unfolding of the C67/73S disulfide bridge variant of At} cyt $c_{6 \mathrm{~A}}$

To assess whether the disulfide bridge in At cyt $c_{6 \mathrm{~A}}$ could be reduced the protein was incubated with dithiothreitol (DTT) overnight in an anaerobic chamber. Attempts to assess the free thiol content of the protein were determined by the reduction of 5,5'-dithiobis(2-nitrobenzoic acid) (DTNB) monitored at $412 \mathrm{~nm}\left(\varepsilon=13500 \mathrm{M}^{-1} \mathrm{~cm}^{-1}\right)$ [42]. The strong absorbance of the heme Soret band $\left(\varepsilon=\sim 100,000 \mathrm{M}^{-1} \mathrm{~cm}^{-1}\right)$ precludes accurate determination of the free thiol content with DTNB and ratios of free thiol to protein were not therefore considered to be an accurate reflection and were consistently lower than a ratio of 2:1 (thiol:protein). Furthermore, DTT reduces ferric heme to the ferrous state. Thus to maintain reduced thiols the presence of excess DTT is required and therefore only the (un)folding of the ferrous form of the protein can be studied. To this end, chemical denaturation was carried out in the presence of $2 \mathrm{mM}$ DTT and the change in $\theta$ at $222 \mathrm{~nm}$ was monitored upon increasing [GuHCl]. These data were fitted using Eq. (1) to give the thermodynamic parameters reported in Table 1.

To circumvent the above problems the $667 / 73 \mathrm{~S}$ cyt $c_{6 \mathrm{~A}}$ variant was used to assess the role of the disulfide in the LIP. The optical (Figure S4 supporting information) and far-UV CD spectra of the disulfide bridge 
A

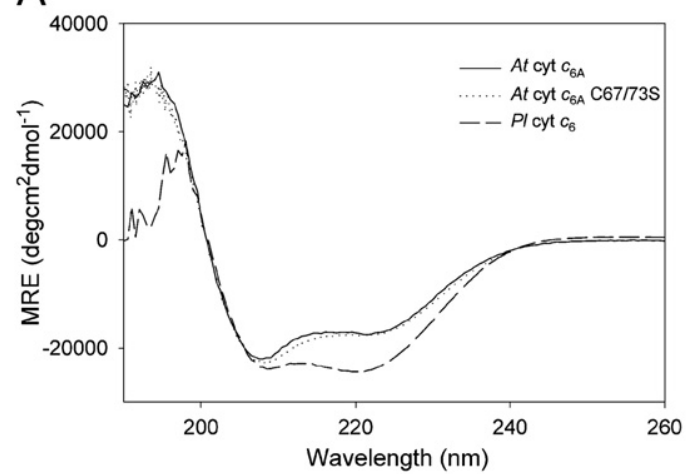

C

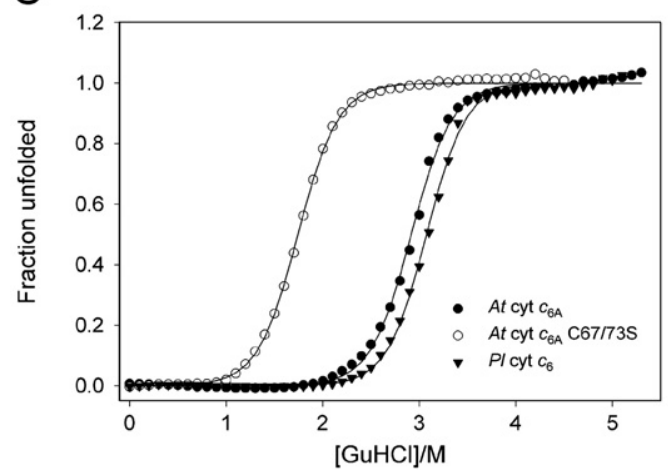

B

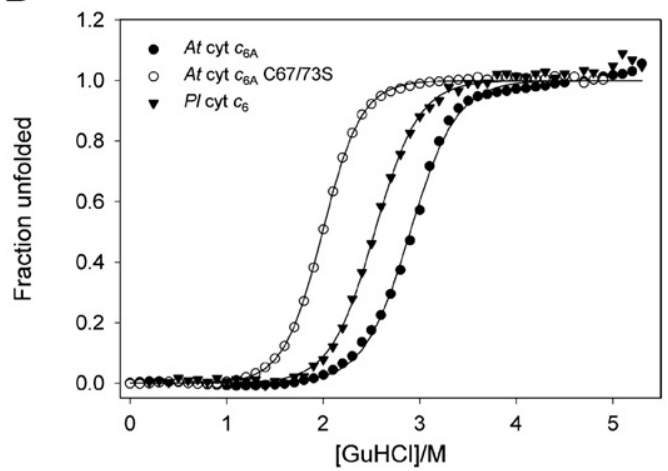

D

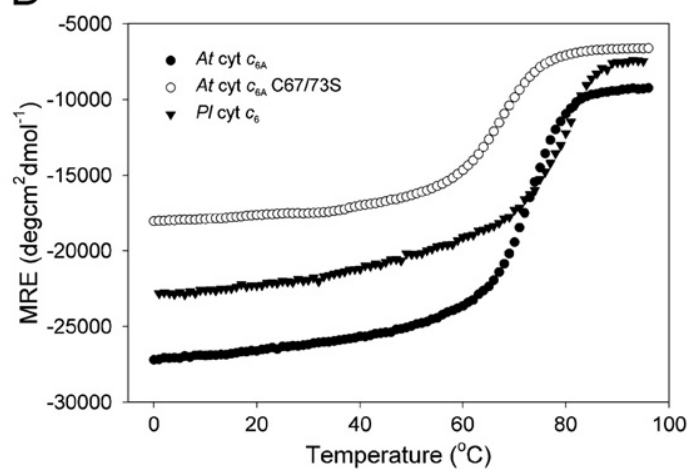

Fig. 2. (A) Far UV-CD spectra of the ferric forms of $A t$ cyt $c_{6 \mathrm{~A}}$, the disulfide variant and $P l c_{1} c_{6}$ at $20^{\circ} \mathrm{C}$ and pH 7. (B-D) Chemical and thermal denaturation profiles obtained through monitoring the changes in ellipticity at $222 \mathrm{~nm}$. Data is shown as fraction unfolded versus increasing [GuHCl] for the ferric (B) and ferrous (C) heme oxidation states and as MRE for increasing temperature in the ferric state (D). The solid lines represent a best fit of the data using equations described in Materials and methods to yield the parameters reported in Table 1.

mutant, C67/73S, are comparable with the wt protein [40] (Fig. 2A), indicating that the removal of this covalent link does not affect the spin-state of the heme or the secondary structure of the protein. In the presence of GuHCl the $\Delta \mathrm{G}_{\mathrm{D}-\mathrm{N}} \mathrm{H}_{2} \mathrm{O}$ and $\mathrm{C}_{\mathrm{m}}$ of the ferric $\mathrm{C} 67 / 73 \mathrm{~S}$ variant have decreased relative to the wt protein by $1.2 \mathrm{kcal} / \mathrm{mol}$ and $0.9 \mathrm{M}$, respectively (Table 1 ). The $m$-value, which is a measure of the change in hydrophobic surface area that has become desolvated upon denaturation, can be used to describe the compactness of the denatured state [43]. In the absence of the disulfide bond an

Table 1

Thermodynamic parameters obtained for the equilibrium unfolding monitored by chemical denaturation using $\mathrm{GuHCl}$ and the estimated thermal mid-point transition $\left(\mathrm{T}_{\mathrm{m}}\right)$ values for wt At cyt $c_{6 \mathrm{~A}}$, the $\mathrm{C} 67 / 73 \mathrm{~S}$ variant and wt $\mathrm{Pl}$ cyt $c_{6}$ at $\mathrm{pH} 7.0$.

\begin{tabular}{lllll}
\hline Protein & ${ }^{\mathrm{a}} \Delta \mathrm{G}_{\mathrm{D}-\mathrm{N}}{ }^{\mathrm{H}_{2} \mathrm{O}}$ & ${ }^{\mathrm{a}} \mathrm{m}$ & ${ }^{\mathrm{a}} \mathrm{C}_{\mathrm{m}}$ & ${ }^{\mathrm{b}} \mathrm{T}_{\mathrm{m}}$ \\
\hline Ferric & & & & \\
At cyt $c_{6 \mathrm{~A}}$ & $7.0(0.2)$ & $2.4(0.1)$ & $2.9(0.1)$ & $73{ }^{\circ} \mathrm{C}$ \\
C67/73S & $5.8(0.1)$ & $2.9(0.1)$ & $2.0(0.1)$ & $67{ }^{\circ} \mathrm{C}$ \\
Pl cyt $c_{6}$ & $6.5(0.2)$ & $2.6(0.1)$ & $2.5(0.1)$ & $82{ }^{\circ} \mathrm{C}$ \\
ferrous & & & & \\
At cyt $c_{6 \mathrm{~A}}$ & $8.1(0.2)$ & $2.8(0.1)$ & $2.9(0.1)$ & $\mathrm{nd}^{\mathrm{d}}$ \\
At cyt $c_{6 A}{ }^{\mathrm{c}}$ & $5.1(0.3)$ & $2.7(0.2)$ & $1.9(0.1)$ & $\mathrm{nd}^{\mathrm{d}}$ \\
C67/73S & $4.9(0.1)$ & $2.8(0.1)$ & $1.8(0.1)$ & $\mathrm{nd}^{\mathrm{d}}$ \\
Pl cyt $c_{6}$ & $8.8(0.2)$ & $2.9(0.1)$ & $3.0(0.1)$ & $\mathrm{nd}^{\mathrm{d}}$ \\
\hline
\end{tabular}

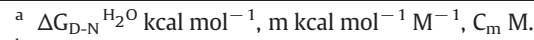

b $\mathrm{T}_{\mathrm{m}}$ is the estimated mid-point of the unfolding transition.

c Carried out in the presence of 2 mM DTT.

d Not determined (nd) due to the inability to keep the heme in a reduced state at elevated temperatures. Values are an average of 3 measurements and numbers in parenthesis indicate the standard deviation between the fitting of the averaged data sets. increase in $m$-value is observed. Removal of a disulfide bridge from the denatured state is anticipated to result in it being less compact. Consequently this will result in a smaller overall $m$-value for the folding reaction. A destabilizing effect upon removal of the disulfide bridge is also apparent from thermal denaturation studies, where the temperature of the mid-point transition is shifted to the left with respect to the wt protein (Fig. 2D). In the ferrous heme state the conformational stability in the absence of the disulfide bond is further compromised, with the $\Delta \mathrm{G}_{\mathrm{D}-\mathrm{N}}{ }^{\mathrm{H}_{2} \mathrm{O}}$ decreasing by $3.2 \mathrm{kcal} / \mathrm{mol}$ and the $C_{m}$ value by $1.1 \mathrm{M}$, resulting in the ferrous form of the variant being less stable than the ferric form by $0.9 \mathrm{kcal} / \mathrm{mol}$ (Table 1 ). It is also noted that these values are similar to those obtained for wt $A t$ cyt $c_{6 \mathrm{~A}}$ in the presence of DTT (Table 1 ). Therefore, removal of the disulfide bridge as in the C67/73S mutant or in the presence of DTT destabilises At cyt $c_{6 \mathrm{~A}}$, with the ferrous heme oxidation state being destabilised to a much greater degree.

\subsection{Folding and unfolding kinetics of the ferric proteins and disulfide variant}

Folding and unfolding kinetics were monitored using stoppedflow far-UV CD spectroscopy. For all proteins studied the folding and unfolding reactions gave monophasic kinetics. Typical folding and unfolding transients, together with fits to a single-exponential function and the resulting residuals are shown in Fig. 3. The dependence of the kinetic rates on $[\mathrm{GuHCl}]$ for At cyt $c_{6 \mathrm{~A}}$ and $P l$ cyt $c_{6}$, together with the disulfide variant is shown in Fig. 4. For all proteins the unfolding limb of the chevron plot is linear within the concentration range of $\mathrm{GuHCl}$ used. However, the folding limb deviates from linearity at low [GuHCl] for all proteins studied (Fig. 4). This behaviour is consistent with the rapid formation of a transient folding 
A

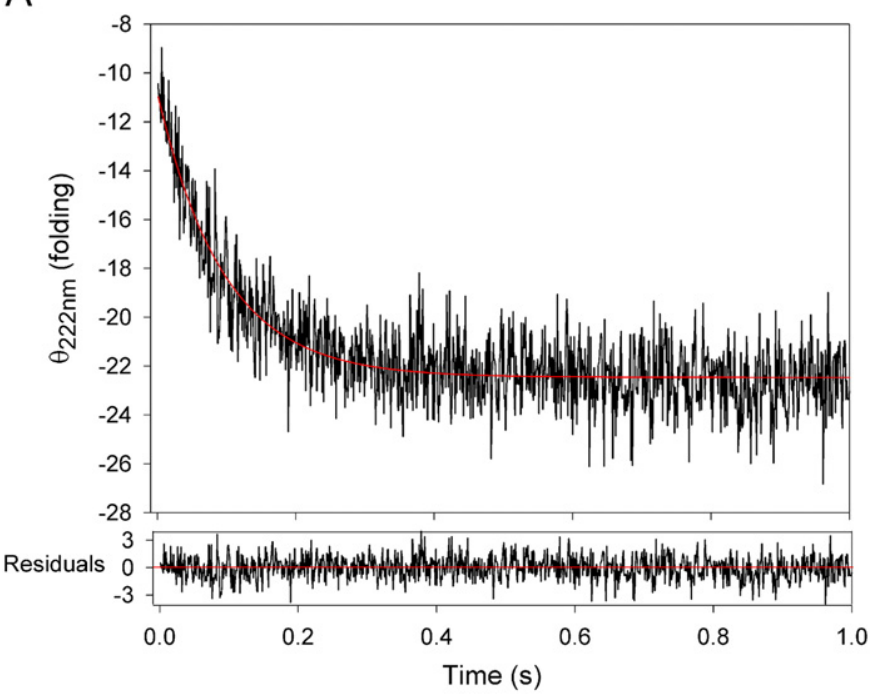

B

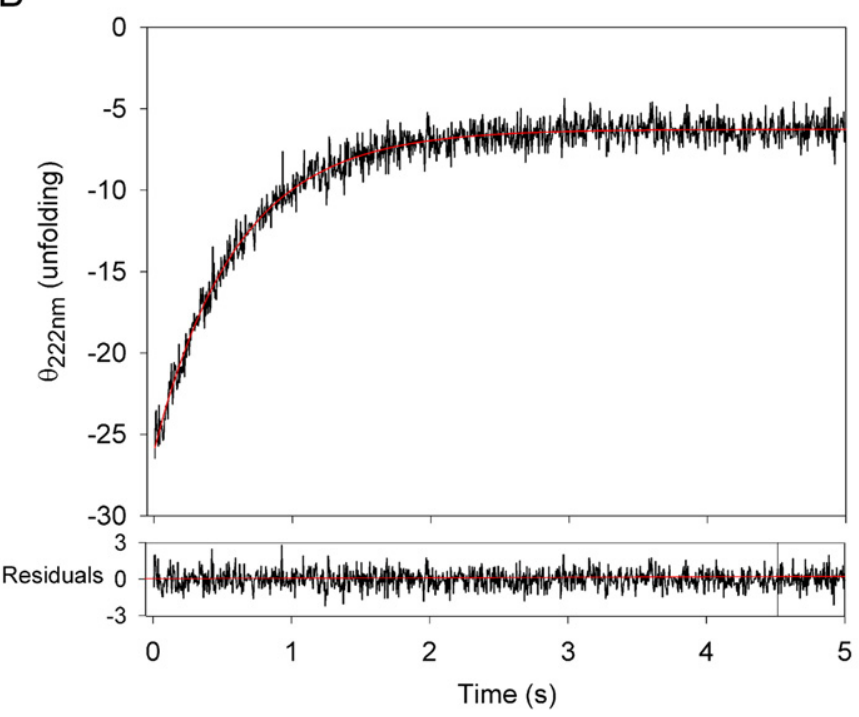

Fig. 3. Examples of folding (A) and unfolding (B) far-UV CD stopped-flow traces for $A t$ ferric cyt $c_{6 \mathrm{~A}}$. The solid red line indicates a fit to a single-exponential function with the residuals shown below. Traces for $P l$ cyt $c_{6}$ and the $667 / 73 \mathrm{~S}$ variant were of equal quality and could all be fitted to a single-exponential function to yield a first-order kinetic rate constant. For interpretation of the references to colour in this figure legend, the reader is referred to the web version of this article.

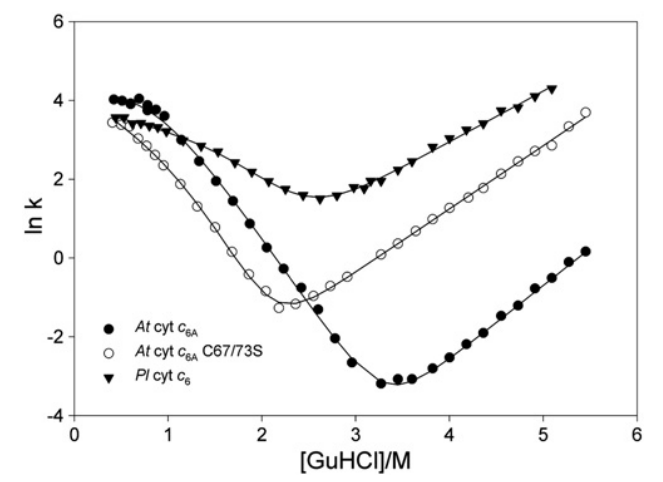

Fig. 4. Chevron plots of data obtained from the stopped-flow folding and unfolding kinetics at $20^{\circ} \mathrm{C}$ and $\mathrm{pH} 7$ for $A t$ ferric cyt $c_{6 \mathrm{~A}}$, the $\mathrm{C} 67 / 73 \mathrm{~S}$ disulfide variant and $\mathrm{Pl}$ ferric cyt $c_{6}$. The folding and unfolding data were fitted globally to a model that assumes the presence of an on-pathway folding intermediate with the solid lines representing the outcomes of the fit. intermediate, which then slowly converts to the native folded state and can be described by the following scheme:

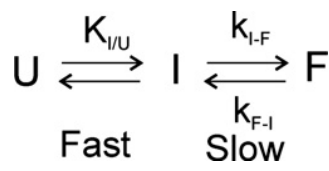

The equilibrium ( $\left.\mathrm{K}_{\mathrm{I} / \mathrm{U}}\right)$ and kinetic parameters $\left(\mathrm{k}_{\mathrm{I}-\mathrm{F}}\right.$ and $\left.\mathrm{k}_{\mathrm{F}-\mathrm{I}}\right)$ were obtained by simultaneously fitting the folding and unfolding data to Eq. (3), which assumes the presence of an on-pathway intermediate. The fits are shown as solid lines in Fig. 4 and the resulting kinetic and equilibrium parameters are reported in Table 2. The agreement between the equilibrium parameters calculated using the kinetic data and the values obtained from the equilibrium denaturation studies with $\mathrm{GuHCl}$, do not align better as expected. However, the trend in overall stability change, is maintained between the kinetic and equilibrium data (Table 2). Moreover, the overall change in helicity agrees well for both chemical denaturation transitions and kinetic transients, suggesting that all parts of the folding pathway have been accounted for and therefore a reason for the discrepancy between data sets is unclear.

The folding rate constant, $\mathrm{k}_{\mathrm{I}-\mathrm{F}}$, for At cyt $c_{6 \mathrm{~A}}$ and $P l$ cyt $c_{6}$ are not significantly different (Table 2 ). This hints at the possibility that the presence of a disulfide bond in At cyt $c_{6 \mathrm{~A}}$ has a negligible effect on the detectable slow folding phase of the pathway. The folding kinetics for the $667 / 73 \mathrm{~S}$ variant strongly supports this, since the $\mathrm{k}_{\mathrm{I}-\mathrm{F}}$ is also not significantly different from wt At cyt $c_{6 \mathrm{~A}}$ or $\mathrm{Pl}$ cyt $c_{6}$ (Table 2). Therefore once the intermediate state has formed the disulfide bond in $A t$ cyt $c_{6 \mathrm{~A}}$ has little influence on the slower phase of the folding pathway. Comparison of the equilibrium constant, $\mathrm{K}_{\mathrm{I} / \mathrm{U}}$ reveals that the intermediate state of $\mathrm{Pl}$ cyt $c_{6}$ is more readily populated than either of the At cyt $c_{6 \mathrm{~A}}$ proteins (Table 2). For the $\mathrm{C67/73S}$ variant, the $\mathrm{K}_{\mathrm{I} / \mathrm{U}}$ is not significantly different from wt At cyt $c_{6 \mathrm{~A}}$ but the $m$ values, $m_{\mathrm{U}}$ and $m_{\mathrm{I}}$, are consistent with a less compact unfolded and intermediate state (Table 2). This is in line with the increase in the equilibrium $m$ value and is again suggestive of less compact unfolded and folding intermediate states.

By contrast the unfolding rates $\left(\mathrm{k}_{\mathrm{F}-\mathrm{I}}\right)$ for the proteins studied, show significant variation (Table 2). The $\mathrm{k}_{\mathrm{F}-\mathrm{I}}$ for $\mathrm{Pl}$ cyt $c_{6}$ is some 4 orders of magnitude faster than At cyt $c_{6 A}$ (Table 2) and removal of the disulfide bond in the latter causes the $\mathrm{k}_{\mathrm{F}-\mathrm{I}}$ to increase by 2-orders of magnitude in the $667 / 73 \mathrm{~S}$ variant relative to the cyt $c_{6 \mathrm{~A}}$ parent molecule. This indicates the possibility that the presence of the disulfide in the LIP between helices 3 and 4 (Fig. 1) increases the stability of the

Table 2

Kinetic and equilibrium parameters for folding and unfolding of wt ferric $P l$ cyt $c_{6}$, At cyt $c_{6 \mathrm{~A}}$ and the $\mathrm{C} 67 / 73 \mathrm{~S}$ variant at $20^{\circ} \mathrm{C}, \mathrm{pH} 7.0$.

\begin{tabular}{llllllll}
\hline Protein & $k_{\mathrm{I}-\mathrm{F}}{ }^{\mathrm{a}}$ & $k_{\mathrm{F}-\mathrm{I}}{ }^{\mathrm{a}}$ & $K_{\mathrm{I} / \mathrm{U}}$ & $m_{\mathrm{U}}{ }^{\mathrm{b}}$ & $m_{\mathrm{I}}{ }^{\mathrm{b}}$ & $m_{\mathrm{T}}{ }^{\mathrm{b}}$ & $\Delta \mathrm{G}_{\mathrm{D}-\mathrm{N}}{ }^{\mathrm{H}_{2} \mathrm{O} \mathrm{c}}$ \\
\hline Pl cyt $c_{6}$ & 46.8 & $0.11(0.01)$ & 63.0 & -4.1 & -1.8 & -1.3 & $5.9(0.2)$ \\
& $(2.6)$ & & $(17.3)$ & $(0.1)$ & $(0.1)$ & $(0.2)$ & \\
At cyt $c_{6 \mathrm{~A}}$ & 76.4 & $4.1 \times 10^{-5}$ & 17.1 & -5.2 & $-1.8^{\mathrm{d}}$ & -1.8 & $10.0(0.2)$ \\
& $(4.9)$ & $(1.1)$ & $(2.9)$ & $(0.1)$ & & $(0.2)$ & \\
C67/73S- $c_{6 \mathrm{~A}}$ & 70.0 & $5.6 \times 10^{-3}$ & 28.2 & -6.0 & -3.1 & -1.6 & $7.4(0.4)$ \\
& $(10.3)$ & $(0.5)$ & $(18.4)$ & $(0.1)$ & $(0.1)$ & $(0.2)$ & \\
\hline
\end{tabular}

a Units of $\mathrm{s}^{-1}$.

c Units kcal mol ${ }^{-1}$. Calculated from kinetic data, $\Delta \mathrm{G}_{\mathrm{D}-\mathrm{N}}{ }^{\mathrm{H}_{2} \mathrm{O}}=-\mathrm{RT} \ln \left(k_{\mathrm{I}-\mathrm{F}}{ }^{*} K_{\mathrm{I} / \mathrm{U}} / k_{\mathrm{F}-\mathrm{I}}\right)$, where $\mathrm{R}$ and $\mathrm{T}$ represent the universal gas constant and the absolute temperature, respectively.

${ }^{d}$ No error exists for the $m_{\mathrm{I}}$ value associated with the At cyt $c_{6 \mathrm{~A}}$ mutant as this value was restrained to that of the $\mathrm{Pl}$ cyt $c_{6}$ protein during the fitting process. Values in parenthesis are the errors from fitting to Eq. (3). 
protein primarily by decelerating the unfolding rate of the molecule. Finally, it is noted that a more shallow chevron plot is observed for $\mathrm{Pl}$ cyt $c_{6}$ (Fig. 4) with lower gradients indicating smaller $m$ values (Table 2) that consequently suggest less hydrophobic material becomes buried or exposed between states.

\section{Discussion}

\subsection{Thermodynamic stability of At cyt $c_{6 A}$ and Pl cyt $c_{6}$}

The folding of a polypeptide chain into a specific tertiary structure is required by many proteins to regulate their biological activity. For cyts $c$, the correct fold of the polypeptide around the covalently attached heme is critical to tuning the $\mathrm{E}_{\mathrm{m}}$, which is ultimately responsible for regulating function [44]. Despite the low sequence identity between cyt $c_{6}$ and cyt $c_{6 \mathrm{~A}}$ the similarity in overall tertiary structure between the two proteins has been well documented with the major difference being the presence in cyt $c_{6 \mathrm{~A}}$ of the disulfide bridged LIP [10]. A difference of $>200 \mathrm{mV}$ in $E_{m}$ between these two proteins therefore belies their similarity in tertiary and heme pocket structure [6] and this large difference in $\mathrm{E}_{\mathrm{m}}$ may have consequences on protein stability.

The overall stability of the ferric fold for At cyt $c_{6 \mathrm{~A}}$ and $P l$ cyt $c_{6}$ determined by chemical denaturation is notably similar $\left(\Delta \mathrm{G}_{\mathrm{D}-\mathrm{N}} \mathrm{H}_{2} \mathrm{O} 6.5-\right.$ $7.0 \mathrm{kcal} / \mathrm{mol}$, Table 1$)$. Comparison with other studies reveal that the $\Delta \mathrm{G}_{\mathrm{D}-\mathrm{N}} \mathrm{H}_{2} \mathrm{O}$ for both proteins are significantly higher than for the photosynthetic cyts $c_{6}$ from the red alga Porphyra yezoensis $\left(\Delta \mathrm{G}_{\mathrm{D}-\mathrm{N}} \mathrm{H}_{2} \mathrm{O}=2.4 \mathrm{kcal} /\right.$ mol) [16] and the bacterium Nostoc sp. PCC $7119\left(\Delta \mathrm{G}_{\mathrm{D}-\mathrm{N}} \mathrm{H}_{2} \mathrm{O}=5.1 \mathrm{kcal} /\right.$ mol) [15]. For $P l$ cyt $c_{6}$ a possible reason for the elevated $\Delta G_{D-N}{ }^{H_{2} \mathrm{O}}$ is due to $\mathrm{Pl}$ being a mild thermophile (optimal growth at $45^{\circ} \mathrm{C}$ ) and proteins from this organism will likely display enhanced stability. For At cyt $c_{6 \mathrm{~A}}$ the higher $\Delta \mathrm{G}_{\mathrm{D}-\mathrm{N}} \mathrm{H}_{2} \mathrm{O}$ may derive in part from the disulfide bond (vide infra).

Burial of the hydrophobic heme in the protein matrix serves to stabilize the neutral ferrous heme relative to the cationic ferric form and this enables $\mathrm{E}_{\mathrm{m}}$ to be maximised through stabilisation of the ferrous state. It has been reported that the ferrous fold of cyts $c$ can convey up to $10 \mathrm{kcal} / \mathrm{mol}$ more resistance to unfolding than the ferric state [45-47]. However, such a large difference is not observed in the present work with only modest gains in the stability of the ferrous fold relative to the ferric states being observed $\left(\Delta \Delta \mathrm{G}_{\mathrm{D}-\mathrm{N}} \mathrm{H}_{2} \mathrm{O}=1.1 \mathrm{kcal} / \mathrm{mol}\right.$ for $A t$ cyt $c_{6 \mathrm{~A}}$ and $\Delta \Delta \mathrm{G}_{\mathrm{D}-\mathrm{N}} \mathrm{H}_{2} \mathrm{O}=2.3 \mathrm{kcal} / \mathrm{mol}$ for $P l$ cyt $\left.c_{6}\right)$. Thus despite the large variance in $E_{m}$ the stability differences between the ferric and ferrous folds are small and imply that there is little difference in the driving force for protein folding between the two oxidation states of the heme for either cyt $c_{6 \mathrm{~A}}$ or cyt $c_{6}$ despite the large difference observed in $\mathrm{E}_{\mathrm{m}}[6-8]$.

\subsection{Contribution of the disulfide bond to At cyt $c_{6 A}$ stability}

Disulfide bonds within proteins are often associated with a structural role [48] but can also have catalytic and redox roles. More recently allosteric disulfide bonds have been identified that are able to control function by triggering a conformational change in the protein upon thiol oxidation $[32,49,50]$. Cyt $c_{6 \mathrm{~A}}$ is unique in the cyt $c_{6}$ family in that it is the only member, so far identified, to contain a disulfide bond and in combination with the low $\mathrm{E}_{\mathrm{m}}$ has led to a number of interesting hypothesis relating to the function of cyt $c_{6 \mathrm{~A}}$ in plants that incorporate catalytic and redox activity of the disulfide [11,12]. A disulfide bond, however, is also present in other Class I cyt $c$ family members $[51,52]$. These can be divided into two categories based on the number of amino acids separating the two disulfide forming Cys residues. For Methylobacterium extorquens cyt $c_{\mathrm{L}}, 113$ amino acids separate the 2 Cys residues and the disulfide bond serves to pin the $\mathrm{N}$-terminal helix to a C-terminal tail [52]. In bullfrog heart cyt $c, 81$ amino acids separate the two Cys residues and the disulfide bond acts to link the $\mathrm{N}$ - and $\mathrm{C}$-terminal helix regions $[53,54]$. The second category has far fewer amino acids separating the two Cys residues and the disulfide bond is found in a loop of varying size. At cyt $c_{6 \mathrm{~A}}$ belongs to this category, with 5 amino acids separating the 2 Cys residues in a loop of 12 amino acids, whereas cyts $c_{5}$ from Azotobacter vinelandii and Shewanella have 2 amino acids separating the Cys residues in loops consisting of 4 amino acids [55-58].

Removal of the disulfide bridge in At cyt $c_{6 \mathrm{~A}}$ does not significantly alter the spectroscopic or secondary structural properties of the C67/ $73 \mathrm{~S}$ variant (Fig. 2A). However, removal of the disulfide bond does cause an overall decrease in thermodynamic stability for both heme oxidation states, with the ferrous form being significantly less stable than the ferric (Fig. 2, Table 1). This observation goes against the paradigm of the ferrous form of cyts $c$ being stabilized over the ferric, yet despite this decreased stability, the $E_{m}$ of the variant is not significantly affected [40]. No effect on $E_{m}$ but a decrease in protein stability has also been reported upon removal of the short, 2 amino acid separated, disulfide bond in the ferric form of cyt $c_{5}$ from Shewanella violacea [58]. This change in stability is more pronounced than for At cyt $c_{6 \mathrm{~A}}$ with the $\Delta \mathrm{G}_{\mathrm{D}-\mathrm{N}} \mathrm{H}_{2} \mathrm{O}$ decreasing by a factor of 2 and the mid-point folding transition decreasing by $24^{\circ} \mathrm{C}$ [58]. This suggests that a shorter connecting disulfide bond infers a higher degree of stability on the cyt $c$ fold in Shewanella cyt $c_{5}$ than the longer, 5 amino acids in At cyt $c_{6 \mathrm{~A}}$. Whether this is a common trend requires further investigation. Nevertheless, the changes in thermodynamic parameters for the C67/73S variant of At cyt $c_{6 \mathrm{~A}}$ in both the ferric and ferrous forms are consistent with a structural role for this disulfide. These findings also support an in silico analysis which classifies this disulfide bond to be structural rather than functional [7,32].

\subsection{A folding intermediate is present in cyt $c_{6 A}$ and cyt $c_{6}$}

The folding kinetics of ferric At cyt $c_{6 \mathrm{~A}}$ and $\mathrm{Pl}$ cyt $c_{6}$ at pH 7 are consistent with the formation of an intermediate species at low denaturant concentrations. At neutral $\mathrm{pH}$ the folding kinetics of ferric cyts $c$ can be complicated because of heme iron mis-coordination by His residues which may interfere with the folding process resulting in multiphasic kinetics and the population of mis-folded intermediates. Lowering the $\mathrm{pH}$, thereby protonating the His residues and abolishing the propensity to ligate to the heme iron, is one way to avoid this misligation [34,59]. For At cyt $c_{6 \mathrm{~A}}$ and $\mathrm{Pl}$ cyt $c_{6}$ only one His is present in their primary structure which is part of the conserved pentapeptide heme binding motif, $\mathrm{CXXCH}$, and is coordinated to the heme iron in both the native and denatured states [60]. Cyt $c_{553}$, like Pl cyt $c_{6}$ and At cyt $c_{6 \mathrm{~A}}$ is another member of the Class I cyt $c$ family that does not contain any additional His residues in its primary structure and at $\mathrm{pH} 7$ the folding pathway is reported to proceed via a two-state mechanism [37]. This is in contrast at $\mathrm{pH} 7$ to At cyt $c_{6 \mathrm{~A}}$ and $\mathrm{Pl}$ cyt $c_{6}$, which in the absence of potential mis-ligated intermediates, fold via an on-pathway intermediate. This finding is aligned with other folding studies on cyt $c$ (albeit at acidic pHs), that have led to the proposal of a consensus folding pathway for this protein family that all involve an on-pathway folding intermediate [35].

Analysis of the $m$ values reported in Table 2 allows Tanford $\beta$-values to be calculated. This is a measure of the fractional burial of solventaccessible surface area relative to the native state (from 0 to 1 ), which correlates to the compactness of a populated species along a reaction coordinate and can therefore can give some insight as to the nature of the intermediate. $A \beta_{\mathrm{I}}$-value of 0.66 has been reported for the folding intermediate in the cyt $c$ family, indicating that about two-thirds of the buried surface area is already formed in the intermediate [35]. In good agreement with this, is the $\beta_{\mathrm{I}}$-value of 0.65 calculated for At cyt $c_{6 \mathrm{~A}}$. For $P l$ cyt $c_{6}$ a $\beta_{\mathrm{I}}$-value of 0.56 is calculated, which is slightly lower than At cyt $c_{6 \mathrm{~A}}$ and the consensus value but nevertheless is consistent with a significant amount of buried surface area formed in the intermediate. From the calculated equilibrium constants, $\mathrm{K}_{\mathrm{I} / \mathrm{U}}$, a higher value for $P l$ cyt $c_{6}$ compared to At cyt $c_{6 \mathrm{~A}}$ is observed and suggests that the Pl cyt $c_{6}$ intermediate is more highly populated (Table 2). 
The high level of compactness of the intermediate suggests that a significant amount of tertiary interactions has formed in the fast kinetic phase of the folding pathway. A substantial body of evidence from cyt $c$ folding kinetics points towards the existence of an intermediate species which has its $\mathrm{N}$ - and C-terminal helices interacting through specific native-like contacts at the helix-helix interface [34,59]. Residues involved in these interactions are largely conserved across the cyt $c$ family and involve at least one strong contact between aromatic groups [14]. An aromatic triangle involving F12/F90/W99 in At cyt $c_{6 \mathrm{~A}}$ and F11/ Y77/W86 in $P l$ cyt $c_{6}$ provides $>13$ inter-atomic contacts. These strong, specific packing interactions are most likely responsible for the mutual recognition of the $\mathrm{N}$ - and C-terminal helices in At cyt $c_{6 \mathrm{~A}}$ and $P l$ cyt $c_{6}$ and aid in the formation of the intermediate on the folding pathway. Thus despite distinct differences in the $\mathrm{E}_{\mathrm{m}}$ and structural elements between cyt $c_{6}$ and cyt $c_{6 \mathrm{~A}}$ certain key elements which are responsible for dictating the folding kinetics and driving the formation of the intermediate are highly conserved.

\subsection{Contribution of the disulfide bond to the folding and unfolding kinetics}

The folding kinetics of the C67/73S variant are very similar to the wt protein. The intermediate is still significantly populated and there is no apparent effect on the $\mathrm{k}_{\mathrm{I}-\mathrm{F}}$ (Table 2). However, a $\beta_{\mathrm{I}}$-value of 0.48 is considerably less than for the wt protein, and suggests that the disulfide bond in cyt $c_{6 \mathrm{~A}}$ is important for determining the relative compactness of the intermediate state and therefore must be considered to act as conformational restraint in both the folding intermediate and the native structure. Despite the more solvent exposed intermediate, the rate $\left(\mathrm{k}_{\mathrm{I}-\mathrm{F}}\right)$ from which this state folds to the native structure in the absence of a disulfide bond is seemingly not affected. This suggests that the location of the disulfide bond, on the periphery of the globular $\alpha$-helical fold, does not influence the slower folding phase in At cyt $c_{6 \mathrm{~A}}$, but the possibility that it influences the rate of formation of the intermediate from the denatured state cannot be ruled out.

In contrast to the folding rates, the unfolding rate for the C67/73S variant is significantly accelerated compared to wt $A t$ cyt $c_{6 \mathrm{~A}}$ (Table 2). However, compared to $\mathrm{Pl}$ cyt $c_{6}$ the At proteins are notably slower, with wt At cyt $c_{6 \mathrm{~A}}$ being at the lower end of unfolding rates reported for mesophilic cyts $c$. The increase in unfolding rate for the $667 / 73 \mathrm{~S}$ variant relative to the $\mathrm{wt}$ protein most likely reflects a destabilization of the folded state [61]. Removal of the At cyt $c_{6 \mathrm{~A}}$ disulfide bond by conservative mutation (C67/73S) decreases the stability of the ferric protein by approximately $1.2 \mathrm{kcal} / \mathrm{mol}$. This decrease in stability for the ferric form of the protein is almost entirely attributable to an increase in the unfolding rate, indicating that the LIP region tethered by this bridge is a late event in At cyt $c_{6 \mathrm{~A}}$ folding.

\subsection{Implications for function}

The experimental evidence presented in this work for the disulfide bond in the LIP of At cyt $c_{6 \mathrm{~A}}$ is consistent with the inference from its geometry that it has a structural rather than a catalytic role [7] and argues against the proposal that cyt $c_{6 \mathrm{~A}}$ functions in the formation of disulfide bonds within other proteins of the thylakoid lumen [12]. Nevertheless, the heme group is redox active, albeit with a much lower $\mathrm{E}_{\mathrm{m}}$ than conventional cyt $c_{6}$, and is capable of transferring electrons onto plastocyanin [10]. Thus a possible role for the LIP is to act as a binding site, stabilized by the disulfide bond, for a partner that acts as a low-potential reductant of the heme.

\section{Acknowledgements}

This work was supported by research funds from the University of Essex (JMM and JARW) and The Leverhulme Trust (CJH). JARW would like to acknowledge Badri Rajagopal for assistance in acquiring some data.

\section{Appendix A. Supplementary data}

Supplementary data to this article can be found online at doi:10. 1016/j.bbapap.2011.10.015.

\section{References}

[1] S. Merchant, B.W. Dreyfuss, Posttranslational assembly of photosynthetic metalloproteins, Annu. Rev. Plant Physiol. Plant Mol. Biol. 49 (1998) 25-51.

[2] R. Gupta, Z. He, S. Luan, Functional relationship of cytochrome $c_{6}$ and plastocyanin in Arabidopsis, Nature 417 (2002) 567-571.

[3] J. Wastl, D.S. Bendall, C.J. Howe, Higher plants contain a modified cytochrome $c_{6}$, Trends Plant Sci. 7 (2002) 244-245.

[4] J. Wastl, S. Purton, D.S. Bendall, C.J. Howe, Two forms of cytochrome $c_{6}$ in a single eukaryote, Trends Plant Sci. 9 (2004) 474-476.

[5] W. Bialek, M. Nelson, K. Tamiola, T. Kallas, A. Szczepaniak, Deeply branching c $c_{6}$-like cytochromes of cyanobacteria, Biochemistry 47 (2008) 5515-5522.

[6] J.A. Worrall, B.G. Schlarb-Ridley, T. Reda, M.J. Marcaida, R.J. Moorlen, J. Wastl, J. Hirst, D.S. Bendall, B.F. Luisi, C.J. Howe, Modulation of heme redox potential in the cytochrome $c_{6}$ family, J. Am. Chem. Soc. 129 (2007) 9468-9475.

[7] J.A. Worrall, B.F. Luisi, B.G. Schlarb-Ridley, D.S. Bendall, C.J. Howe, Cytochrome c $c_{6 A}$ : discovery, structure and properties responsible for its low haem redox potential, Biochem. Soc. Trans. 36 (2008) 1175-1179.

[8] F.P. Molina-Heredia, J. Wastl, J.A. Navarro, D.S. Bendall, M. Hervas, C.J. Howe, M.A. De La Rosa, Photosynthesis: a new function for an old cytochrome? Nature 424 (2003) 33-34.

[9] H. Chida, T. Yokoyama, F. Kawai, A. Nakazawa, H. Akazaki, Y. Takayama, T. Hirano, K. Suruga, T. Satoh, S. Yamada, R. Kawachi, S. Unzai, T. Nishio, S.Y. Park, T. Oku, Crystal structure of oxidized cytochrome $\mathrm{c}_{6 \mathrm{~A}}$ from Arabidopsis thaliana, FEBS Lett. 580 (2006) 3763-3768.

[10] M.J. Marcaida, B.G. Schlarb-Ridley, J.A. Worrall, J. Wastl, T.J. Evans, D.S. Bendall, B.F. Luisi, C.J. Howe, Structure of cytochrome $\mathrm{c}_{6 \mathrm{~A}}$, a novel dithio-cytochrome of Arabidopsis thaliana, and its reactivity with plastocyanin: implications for function, J. Mol. Biol. 360 (2006) 968-977.

[11] C.J. Howe, B.G. Schlarb-Ridley, J. Wastl, S. Purton, D.S. Bendall, The novel cytochrome $c_{6}$ of chloroplasts: a case of evolutionary bricolage? J. Exp. Bot. 57 (2006) 13-22.

[12] B.G. Schlarb-Ridley, R.H. Nimmo, S. Purton, C.J. Howe, D.S. Bendall, Cytochrome $\mathrm{C}_{6 \mathrm{~A}}$ is a funnel for thiol oxidation in the thylakoid lumen, FEBS Lett. 580 (2006) 2166-2169.

[13] C. Lange, M. Hervas, M.A. De la Rosa, Analysis of the stability of cytochrome $c_{6}$ with an improved stopped-flow protocol, Biochem. Biophys. Res. Commun. 310 (2003) 215-221.

[14] O.B. Ptitsyn, Protein folding and protein evolution: common folding nucleus in different subfamilies of c-type cytochromes? J. Mol. Biol. 278 (1998) $655-666$.

[15] C. Lange, I. Luque, M. Hervas, J. Ruiz-Sanz, P.L. Mateo, M.A. De la Rosa, Role of the surface charges D72 and K8 in the function and structural stability of the cytochrome $\mathrm{c}$ from Nostoc sp. PCC 7119, FEBS J. 272 (2005) 3317-3327.

[16] T. Satoh, A. Itoga, Y. Isogai, M. Kurihara, S. Yamada, M. Natori, N. Suzuki, K. Suruga, R. Kawachi, M. Arahira, T. Nishio, C. Fukazawa, T. Oku, Increasing the conformational stability by replacement of heme axial ligand in c-type cytochrome, FEBS Lett. 531 (2002) 543-547.

[17] G.A. Elove, A.K. Bhuyan, H. Roder, Kinetic mechanism of cytochrome c folding: involvement of the heme and its ligands, Biochemistry 33 (1994) 6925-6935.

[18] H. Roder, G.A. Elove, S.W. Englander, Structural characterization of folding intermediates in cytochrome c by H-exchange labelling and proton NMR, Nature 335 (1988) 700-704.

[19] T.R. Sosnick, L. Mayne, R. Hiller, S.W. Englander, The barriers in protein folding, Nat. Struct. Biol. 1 (1994) 149-156.

[20] W. Colon, L.P. Wakem, F. Sherman, H. Roder, Identification of the predominant non-native histidine ligand in unfolded cytochrome c, Biochemistry 36 (1997) 12535-12541.

[21] B.S. Russell, R. Melenkivitz, K.L. Bren, NMR investigation of ferricytochrome c unfolding: detection of an equilibrium unfolding intermediate and residual structure in the denatured state, Proc. Natl. Acad. Sci. U. S. A. 97 (2000) 8312-8317.

[22] B.S. Russell, K.L. Bren, Denaturant dependence of equilibrium unfolding intermediates and denatured state structure of horse ferricytochrome c, J. Biol. Inorg. Chem. 7 (2002) 909-916.

[23] P.D. Barker, S.J. Ferguson, Still a puzzle: why is haem covalently attached in c-type cytochromes? Structure 7 (1999) R281-R290.

[24] A. Borgia, S. Gianni, M. Brunori, C. Travaglini-Allocatelli, Fast folding kinetics and stabilization of apo-cytochrome c, FEBS Lett. 582 (2008) 1003-1007.

[25] A.H. Ullah, K. Sethumadhavan, E.J. Mullaney, Monitoring of unfolding and refolding in fungal phytase (phyA) by dynamic light scattering, Biochem. Biophys. Res. Commun. 327 (2005) 993-998.

[26] M.J. Feige, F. Hagn, J. Esser, H. Kessler, J. Buchner, Influence of the internal disulfide bridge on the folding pathway of the CL antibody domain, J. Mol. Biol. 365 (2007) 1232-1244.

[27] C. Parrini, F. Bemporad, A. Baroncelli, S. Gianni, C. Travaglini-Allocatelli, J.E. Kohn, M. Ramazzotti, F. Chiti, N. Taddei, The folding process of acylphosphatase from Escherichia coli is remarkably accelerated by the presence of a disulfide bond, J. Mol. Biol. 379 (2008) 1107-1118. 
[28] A.H. Ullah, K. Sethumadhavan, E.J. Mullaney, Unfolding and refolding of Aspergillus niger PhyB phytase: role of disulfide bridges, J. Agric. Food Chem. 56 (2008) 8179-8183.

[29] J.M. Mason, M.J. Cliff, R.B. Sessions, A.R. Clarke, Low energy pathways and nonnative interactions: the influence of artificial disulfide bridges on the mechanism of folding, J. Biol. Chem. 280 (2005) 40494-40499.

[30] J.M. Mason, N. Gibbs, R.B. Sessions, A.R. Clarke, The influence of intramolecular bridges on the dynamics of a protein folding reaction, Biochemistry 41 (2002) 12093-12099.

[31] C.N. Pace, E.J. Hebert, K.L. Shaw, D. Schell, V. Both, D. Krajcikova, J. Sevcik, K.S. Wilson, Z. Dauter, R.W. Hartley, G.R. Grimsley, Conformational stability and thermodynamics of folding of ribonucleases Sa, Sa2 and Sa3, J. Mol. Biol. 279 (1998) 271-286

[32] B. Schmidt, L. Ho, P.J. Hogg, Allosteric disulfide bonds, Biochemistry 45 (2006) 7429-7433.

[33] S. Gianni, C. Travaglini-Allocatelli, F. Cutruzzola, M.G. Bigotti, M. Brunori, Snapshots of protein folding. A study on the multiple transition state pathway of cytochrome $c_{551}$ from Pseudomonas aeruginosa, J. Mol. Biol. 309 (2001) 1177-1187.

[34] C. Travaglini-Allocatelli, S. Gianni, V. Morea, A. Tramontano, T. Soulimane, M. Brunori, Exploring the cytochrome $\mathrm{c}$ folding mechanism: cytochrome $\mathrm{c}_{552}$ from thermus thermophilus folds through an on-pathway intermediate, J. Biol. Chem. 278 (2003) 41136-41140.

[35] C. Travaglini-Allocatelli, S. Gianni, M. Brunori, A common folding mechanism in the cytochrome c family, Trends Biochem. Sci. 29 (2004) 535-541.

[36] C. Travaglini-Allocatelli, S. Gianni, V.K. Dubey, A. Borgia, A. Di Matteo, D. Bonivento, F. Cutruzzola, K.L. Bren, M. Brunori, An obligatory intermediate in the folding pathway of cytochrome $c_{552}$ from Hydrogenobacter thermophilus, J. Biol. Chem. 280 (2005) 25729-25734.

[37] J. Guidry, P. Wittung-Stafshede, Cytochrome $c_{553}$, a small heme protein that lacks misligation in its unfolded state, folds with rapid two-state kinetics, J. Mol. Biol. 301 (2000) 769-773.

[38] J.M. Sauder, N.E. MacKenzie, H. Roder, Kinetic mechanism of folding and unfolding of Rhodobacter capsulatus cytochrome c $c_{2}$, Biochemistry 35 (1996) 16852-16862.

[39] E. Arslan, H. Schulz, R. Zufferey, P. Kunzler, L. Thony-Meyer, Overproduction of the Bradyrhizobium japonicum c-type cytochrome subunits of the cbb3 oxidase in Escherichia coli, Biochem. Biophys. Res. Commun. 251 (1998) 744-747.

[40] J. Wastl, F.P. Molina-Heredia, M. Hervas, J.A. Navarro, M.A. De la Rosa, D.S. Bendall, C.J. Howe, Redox properties of Arabidopsis cytochrome $c_{6}$ are independent of the loop extension specific to higher plants, Biochim. Biophys. Acta 1657 (2004) 115-120.

[41] M.M. Santoro, D.W. Bolen, A test of the linear extrapolation of unfolding free energy changes over an extended denaturant concentration range, Biochemistry 31 (1992) 4901-4907.

[42] G.L. Ellman, Tissue sulfhydryl groups, Arch. Biochem. Biophys. 82 (1959) 70-77.

[43] J.K. Myers, C.N. Pace, J.M. Scholtz, Denaturant M-values and heat-capacity changesrelation to changes in accessible surface-areas of protein unfolding, Protein Sci. 4 (1995) 2138-2148.

[44] F.A. Tezcan, J.R. Winkler, H.B. Gray, Effects of ligation and folding on reduction potentials of heme proteins, J. Am. Chem. Soc. 120 (1998) 13383-13388.
[45] D.S. Cohen, G.J. Pielak, Entropic stabilization of cytochrome c upon reduction, J. Am. Chem. Soc. 117 (1995) 1675-1677.

[46] G.A. Mines, T. Pascher, S.C. Lee, J.R. Winkler, H.B. Gray, Cytochrome c folding triggered by electron transfer, Chem. Biol. 3 (1996) 491-497.

[47] T. Pascher, J.P. Chesick, J.R. Winkler, H.B. Gray, Protein folding triggered by electron transfer, Science 271 (1996) 1558-1560.

[48] C.N. Pace, Measuring and increasing protein stability, Trends Biotechnol. 8 (1990) 93-98.

[49] P.J. Hogg, Disulfide bonds as switches for protein function, Trends Biochem. Sci. 28 (2003) 210-214.

[50] H. Chen, J. Hu, P.R. Chen, L. Lan, Z. Li, L.M. Hicks, A.R. Dinner, C. He, The Pseudomonas aeruginosa multidrug efflux regulator MexR uses an oxidation-sensing mechanism, Proc. Natl. Acad. Sci. U. S. A. 105 (2008) 13586-13591.

[51] G.R. Moore, G.W. Pettigrew, Cytochrome c: Evolutionary, Structural and Physicochemical Aspects, Springer-Verlag, London, 1990.

[52] P. Williams, L. Coates, F. Mohammed, R. Gill, P. Erskine, D. Bourgeois, S.P. Wood, C. Anthony, J.B. Cooper, The 1.6 ̊ X-ray structure of the unusual c-type cytochrome, cytochrome $\mathrm{c}_{\mathrm{L}}$, from the methylotrophic bacterium Methylobacterium extorquens, J. Mol. Biol. 357 (2006) 151-162.

[53] D.N. Brems, R. Cass, E. Stellwagen, Conformational transitions of frog heart ferricytochrome c, Biochemistry 21 (1982) 1488-1493.

[54] S.F. Betz, G.J. Pielak, Introduction of a disulfide bond into cytochrome c stabilizes a compact denatured state, Biochemistry 31 (1992) 12337-12344.

[55] D.C. Carter, K.A. Melis, S.E. O'Donnell, B.K. Burgess, W.R. Furey Jr, B.C. Wang, C.D. Stout, Crystal structure of Azotobacter cytochrome $C_{5}$ at $2.5 \AA$ resolution, J. Mol. Biol. 184 (1985) 279-295.

[56] I. Bertini, G. Cavallaro, A. Rosato, Cytochrome c: occurrence and functions, Chem. Rev. 106 (2006) 90-115.

[57] I. Bartalesi, I. Bertini, P. Hajieva, A. Rosato, P.R. Vasos, Solution structure of a monoheme ferrocytochrome c from Shewanella putrefaciens and structural analysis of sequence-similar proteins: functional implications, Biochemistry 41 (2002) 5112-5119.

[58] K. Ogawa, T. Sonoyama, T. Takeda, S. Ichiki, S. Nakamura, Y. Kobayashi, S Uchiyama, K. Nakasone, S.J. Takayama, H. Mita, Y. Yamamoto, Y. Sambongi, Roles of a short connecting disulfide bond in the stability and function of psychrophilic Shewanella violacea cytochrome $c_{5}$, Extremophiles 11 (2007) 797-807.

[59] W. Colon, G.A. Elove, L.P. Wakem, F. Sherman, H. Roder, Side chain packing of the $\mathrm{N}$ - and C-terminal helices plays a critical role in the kinetics of cytochrome $\mathrm{c}$ folding, Biochemistry 35 (1996) 5538-5549.

[60] J. Babul, E. Stellwagen, The existence of heme-protein coordinate-covalent bonds in denaturing solvents, Biopolymers 10 (1971) 2359-2361.

[61] A.M. Beasty, M.R. Hurle, J.T. Manz, T. Stackhouse, J.J. Onuffer, C.R. Matthews, Effects of the phenylalanine-22--leucine, glutamic acid-49--methionine, glycine-234--aspartic acid, and glycine-234--lysine mutations on the folding and stability of the alpha subunit of tryptophan synthase from Escherichia coli, Biochemistry 25 (1986) 2965-2974. 